\title{
Mesomorphic Properties and Computer Simulation of Guanazole Derivatives and Their Mixtures
}

\author{
D.O. Moskvin ${ }^{a}$, V.V. Sotsky ${ }^{a}$, E.A. DANilova ${ }^{b}$ \\ T.V. KudAYAROVA ${ }^{b}$, A.I. SMIRNOVA ${ }^{a}$, N.V. UsOL'TSEVA ${ }^{a, *}$ \\ ${ }^{a}$ Nanomaterials Research Institute, Ivanovo State University, Ermak str., 37/7, 153025 Ivanovo, Russia \\ ${ }^{b}$ Ivanovo State University of Chemistry and Technology, Sheremetevsky pr., 7, 153000 Ivanovo, Russia \\ An investigation of the mesomorphic properties of 3,5-diamino-1-dodecyl-1,2,4-triazole and 3-amino-1,5- \\ dodecyl-1,2,4-triazole binary mixture in the ratio of 1:0.75 (four molecules of the first compound and three of \\ the second) was performed. By means of polarizing optical microscopy, it was discovered that the experimen- \\ tally obtained binary mixture possesses enantiotropic mesomorphic properties (SmA phase). With the help of the \\ molecular dynamics simulation of both individual triazole derivatives and their binary mixture, it was shown that \\ the SmA-mesophase is caused by the presence of the di-dodecyl substituted triazole derivative.
}

DOI: 10.12693 /APhysPolA.127.950

PACS: $02.70 \mathrm{Ns}, 65.90+\mathrm{i}$

\section{Introduction}

3,5-Diamino-1H-1,2,4-triazole (guanazole) is widely used as a starting material in the synthesis of macrocyclic compounds [1-4]. Guanazole derivatives can be applied in many industrial sectors such as herbicides, medical drugs, emulsion stabilizers, cationic dyes and so on. Alkylated guanazole derivatives, which are soluble in organic solvents, can acquire a wider practical use, particularly in medicine [5].

The synthetic approach to alkylation of 3,5-diaminotriazole is well known [6], but the most difficult and timeconsuming step of the synthesis is the isolation and purification of the target alkylated products. Due to the complexity of the target product purification, it is reasonable to precede this process with computer simulation in order to get a prediction concerning the supramolecular organization and mesomorphic properties of the target compounds.

\section{Materials and methods}

The subjects of the research are 3,5-diamino1-dodecyl-1,2,4-triazole (I), 3-amino-1,5-dodecyl-1,2,4triazole (II) (Fig. 1) and their binary mixture in the ratio of 1:0.75 (III) (i.e. four molecules of the first compound to three of the second). The component ratio of the binary mixture III was determined by experimental investigations [7]. The synthetic procedure for alkylation is described in [8]. Compounds I and II, at present are not yet isolated from the binary mixture III, obtained from the synthesis.

The mesomorphic properties of the experimentally obtained binary mixture III were investigated by polarizing optical microscopy (POM) (Leitz Laborlux 12 Pol

* corresponding author; e-mail: nv_usoltseva@mail.ru

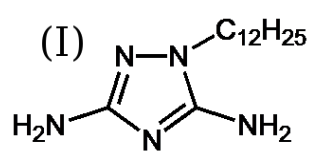

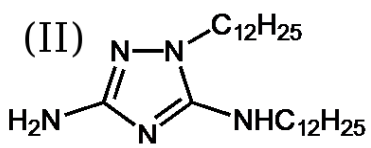

Fig. 1. Structural formula of 3,5-diamino-1-dodecyl1,2,4-triazole (I) and 3-amino-1,5-dodecyl-1,2,4-triazole (II).

equipped with a Mettler FP5 hot stage), heating/cooling rate of $5{ }^{\circ} \mathrm{C} \min ^{-1}$.

The computer simulation was carried out using the molecular dynamics (MD) method with molecular mechanics (MM) parameters [9] and the Euler method [10] was used to solve the equations of motion. The temperature and pressure control were secured by the Berendsen's thermostat and barostat [11], respectively. The MM model shown in Eq. 1 was chosen for the MD simulation:

$$
\begin{aligned}
U & =\sum_{b \in \Gamma_{1}} k_{b}\left(r_{b}-r_{b 0}\right)^{2}+\sum_{\alpha \in \Gamma_{2}} k_{\alpha}\left(\alpha-\alpha_{0}\right)^{2} \\
& +\sum_{\phi \in \Phi} \frac{V_{\phi}}{2}\left(1+\cos \left(n_{\phi} \varphi+\varphi_{0}\right)\right) \\
& +\sum_{i} \sum_{j \neq i}\left(\left(\frac{A_{i}}{r_{i j}^{12}}-\frac{B_{j}}{r_{i j}^{6}}\right)+\frac{q_{i} q_{j}}{4 \pi \varepsilon \varepsilon_{0} r_{i j}}\right),
\end{aligned}
$$

where $U$ is potential energy of the system; $k_{b}, k_{\alpha}, V_{\varphi}$ are elastic constants for valence bonds, valence angles and dihedral angles, respectively; $r_{b}$ is the bond length at the current moment of time; $r_{b 0}$ is the equilibrium bond length; $\Gamma_{1}, \Gamma_{2}, \Phi$ are sets of all valence bonds, valence angles and dihedral angles of the system, respectively; $\alpha$ is the valence angle at the current moment of time; $\alpha_{0}$ is the equilibrium valence angle; $\varphi$ is the dihedral angle value at the current moment of time; $n_{\varphi}$ is the dihedral barrier ratio; $\varphi_{0}$ is the initial phase, $A_{i}, B_{j}$ are van 
der Waals interactions potential parameters; $r_{i j}$ is interatomic distance between $i$ and $j$ atoms; $q_{i}, q_{j}$ are atomic charges of $i$ and $j$ atoms; $\varepsilon$ is permittivity of medium; $\varepsilon_{0}$ is permittivity of the vacuum.

The above-mentioned potentials and their constants (excluding charges) are taken from the AMBER force field [12]. The charges were calculated by the HartreeFock method in the 6-311G basis set with the help of GAMESS computer program [13]. MD simulations were carried out by 'MDSimGrid-GPU' computer program [14] that performs MD simulation on graphics processing units (GPU). This program allowed the simulation time to be reduced by a factor of ten.

\section{Results and discussion}

\subsection{Mesomorphic properties of the guanazole derivatives binary mixture}

The study of the binary mixture III by polarizing optical microscopy revealed that it forms an enantiotropic SmA phase. On heating, the SmA phase was observed between 110 and $113{ }^{\circ} \mathrm{C}$ and on cooling it showed a typical texture with myelin figures (Fig. 2a) between 111 and $103{ }^{\circ} \mathrm{C}$. On cooling from the isotropic liquid, it first appeared in the form of battonets (Fig. 2b), which then transformed quickly into a homeotropic texture with birefringence visible only around air bubbles (Fig. 2c).
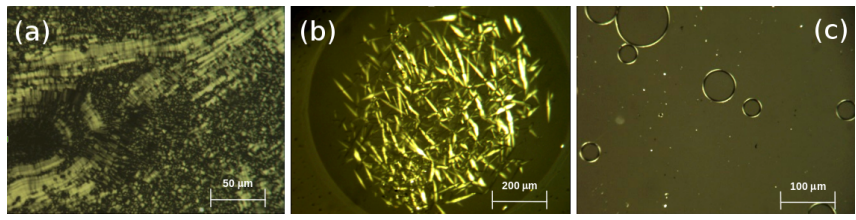

Fig. 2. Photomicrographs of the binary mixture III: a) myelin figures in $\mathrm{SmA}$ phase, $T=111^{\circ} \mathrm{C}$, on heating, b) battonets of the $\mathrm{SmA}$ phase appearing from isotropic liquid, $T=111^{\circ} \mathrm{C}$, on cooling, c) homeotropic texture of SmA phase, $T=106^{\circ} \mathrm{C}$, on cooling.

\subsection{Computer simulation of guanazole derivatives supramolecular organization}

MD simulation of the supramolecular organization of the individual compounds I and II was carried out to clarify which of them causes mesomorphic properties of the binary mixture III. First, however, it was necessary to perform a simulation of the binary mixture III, in order to ensure that the model is suitable for the identification of mesomorphism of this class of compound.

The modeling was performed as follows: the simulated system had comprised 140 molecules ( 80 molecules of compound I and 60 molecules of compound II) and periodic boundary conditions were superposed on the system; the external pressure was $1 \mathrm{~atm}$. The simulation was carried out at $107{ }^{\circ} \mathrm{C}$ (on cooling) and the system monitoring interval was $10 \mathrm{~ns}$. When the simulation was
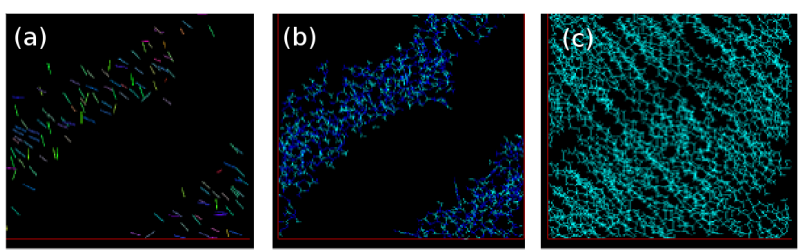

Fig. 3. Supramolecular organization of the binary mixture III: a) - only vectors connecting two nitrogen atoms of the central fragment of molecules are shown, b) - only central fragments of molecules including $\mathrm{NH}_{2}$-groups are shown, c) - only alkyl substituents of molecules are shown.

completed, the SmA-mesophase of the binary mixture III was identified by visual analysis (Fig. 3).

Next, a series of computational experiments, modeling of the supramolecular organization of the individual compounds I and II, was performed, according to the following scheme. At the first stage, two systems of 160 molecules each (compound I and compound II) were assembled. The periodic boundary conditions were superposed on both systems and the external pressure was set to $1 \mathrm{~atm}$. The systems monitoring intervals were 10 and $40 \mathrm{~ns}$, respectively. The simulations were performed at $112{ }^{\circ} \mathrm{C}$ for compound I and at $113{ }^{\circ} \mathrm{C}$ for compound II. The choice of the simulation temperatures was based on the assumption that the presence of the impurities usually leads to a decrease in melting points. The analysis of the performed MD simulations established that the system of compound II showed layered supramolecular organization corresponding to a SmA phase (Fig. 4). As for the system of compound I, such layered organization was not found (Fig. 5).
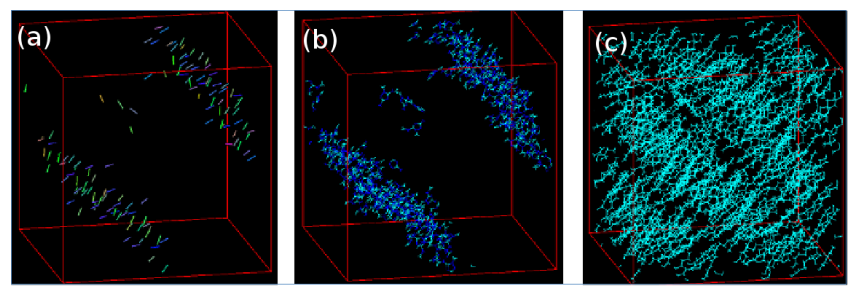

Fig. 4. Supramolecular organization of compound II: a) - only vectors connecting two nitrogen atoms of the central fragment of molecules are shown, b) - only central fragments of molecules including $\mathrm{NH}_{2}$-groups are shown, c) - only alkyl substituents of molecules are shown.

Thus, the results of the performed computational experiments show that mesomorphic properties of the binary mixture III are likely caused by the dialkylsubstituted derivative II. It should be emphasized that at this stage of work, the binary mixture III has not yet been separated into individual components.

\section{Conclusions}

A binary mixture of mono- and di-dodecyl substituted triazole derivatives with the component ratio of 1:0.75, 

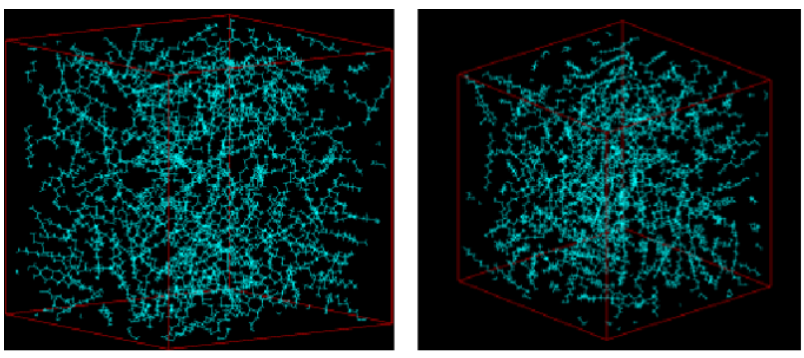

Fig. 5. Supramolecular organization of compound I (only alkyl substituents are shown) from different view angles.

respectively, was synthesised. Investigation of the mesomorphic properties showed that it exhibits an enantiotropic SmA mesophase. The complexity of separation did not allow pure, individual components to be obtained and to prove experimentally which of them is responsible for the mesophase formation. MD simulation carried out by "MDSimGrid-GPU" computer program, developed by us, showed that it is di-alkylsubstituted component that caused the appearance of SmA phase in the binary mixture.

\section{Acknowledgments}

The work was supported by the program of the Ministry of Education and Science of the Russian Federation for Ivanovo State University, to perform research work in 2014-2016 (Grant 4.106.2014K) and for Ivanovo State University of Chemistry and Technology (the basic part of the state assignment for the scientific researchers 795). The authors are thankful to prof. D.W. Bruce for valuable comments.

\section{References}

[1] M.K. Islyaikin, E.A. Danilova, Yu.V. Romanenko, O.G. Khelevina, T.N. Lomova, Chemical Processes with Participation of Biological and Related Compounds, Eds. T.N. Lomova, G.E. Zaikov, BRILL, Leiden-Boston, 2008, p. 219.
[2] Yu.V. Romanenko, E.A. Danilova, O.G. Khelevina, M.K. Islyaikin, Mend. Comm. 18, 82 (2008).

[3] M.K. Islyaikin, E.A. Danilova, Russian Chemical Bulletin. International Edition 5, 689 (2007).

[4] G. de la Torre, T. Torres, J. Org. Chem. 61, 6446 (1996).

[5] K.M. Kadish, K.M. Smith, Handbook of Porphyrine Science: with applications to chemistry, physics, materials science, engineering, biology and medicine, (volumes 16-20), World Scientific Publishing Co. Pte. Ltd., London 2012.

[6] J.J. Fuentes, J.A. Lenoir, Can. J. Chem. 54, 3620 (1976).

[7] A.A. Vorontsova, E.A. Danilova, T.V. Melenchuk, M.K. Islaykin, New directions in heterocyclic compounds chemistry, Conference Proceedings, Pyatigorsk, Russia 2013, p. 159 (in Russian).

[8] E.A. Danilova, A.A. Ivolin, A.A. Vorontsova, M.K. Islaykin, G.A. Ananyeva, N.V. Zharnikova, V.V. Bykova, N.V. Usol'tseva, Liquid Crystalls and Their Application 3, 5 (2011) (in Russian).

[9] N.V. Usol'tseva, F.N. Yasinskiy, V.V. Sotsky, M.S. Kostin, Vestnik IGEU 4, 45 (2009) (in Russian).

[10] V.M. Verzhbitsky, Numerical Methods: Mathematical Analysis and Ordinary Differential Equations, Vyschaya shkola, Moscow 2001 (in Russian).

[11] H.J.C. Berendsen, J.P.M. Postma, W.F. van Gunsteren, A. DiNola, J.R. Haak J. Chem. Phys. 81, 3684 (1984).

[12] W.D. Cornell, P. Cieplak, C.I. Bayly, I.R. Gould, K.M. Merz, Jr., D. M. Ferguson, D.C. Spellmeyer, T. Fox, J.W. Caldwell, P.A. Collman, J. Am. Chem. Soc. 117, 5179 (1995).

[13] M.W. Schmidt, K.K. Baldridge, J.A. Boatz, S.T. Elbert, M.S. Gordon, J.H. Jensen, S. Koseki, N. Matsunaga, K.A. Nguyen, S.J. Su, T.L. Windus, M. Dupuis, J.A. Montgomery, J. Comput. Chem. 14, 1347 (1993).

[14] V.V. Sotsky, Russian Patent No 2011613854, (18 May 2011) (in Russian). 